\title{
A institucionalização da Economia Criativa no estado de Mato Grosso do Sul
}

The institutionalization of Creative Economy in the state of Mato Grosso do Sul

La institucionalización de la Economía Creativa en el estado de Mato Grosso do Sul

\author{
Vanessa Pancheri Teixeira ${ }^{1}$ \\ William Teixeira ${ }^{1}$ \\ Elcio Gustavo Benini ${ }^{1}$
}

Recebido em 02/03/2018; revisado e aprovado em 11/05/2018; aceito em 14/05/2018

DOI: http://dx.doi.org/10.20435/inter.v20i4.1864

\begin{abstract}
Resumo: Este trabalho tem como objeto de pesquisa a Economia Criativa enquanto política pública. Seu objetivo é analisar o processo de institucionalização da Economia Criativa em Mato Grosso do Sul. O campo empírico-particular da pesquisa é constituído pela análise de documentos oficiais disponíveis no Diário Oficial do estado de Mato Grosso do Sul. Por meio da pesquisa qualitativa e através da análise documental, buscou-se levantar o estado da Economia Criativa na administração pública estadual
\end{abstract}

Palavras-chave: Economia Criativa; políticas públicas; Mato Grosso do Sul..

Abstract: This paper aims to research the Creative Economy as public policy. Its objective is to analyze the process of institutionalization of the Creative Economy in the state of Mato Grosso do Sul. The empirical field of research is constituted by the analysis of official documents available at the Official Gazette of the state of Mato Grosso do Sul. Through qualitative research and the documentary analysis it was sought to systematize the status of Creative Economy in the public administration

Keywords: Creative Economy; public policy; Mato Grosso do Sul

Resumen: Este trabajo tiene como objeto de investigación la Economía Creativa como política pública. Su objetivo es analizar el proceso de institucionalización de la Economía Creativa en Mato Grosso do Sul. El campo empírico-particular de la investigación está constituido por el análisis de documentos oficiales disponibles en el Diario Oficial del estado de Mato Grosso do Sul. A través de la investigación cualitativa y del análisis documental, se buscó levantar el estado de la Economía Creativa en la administración pública estadual.

Palabras clave: Economía Creativa; políticas públicas; Mato Grosso do Sul.

\section{INTRODUÇÃO}

A criatividade e a inovação têm se apresentado como estratégias para enfrentar situações complexas em tempos de crise, como apontado pelo Mapeamento da Indústria Criativa no Brasil (FEDERAÇÃO DAS INDÚSTRIAS DO ESTADO DO RIO DE JANEIRO [FIRJAN], 2016), e conceitos como Indústria Criativa e Economia Criativa começam a ganhar lugar na agenda das políticas públicas, como ressaltam Dalla Costa e Souza-Santos (2011, p. 151) ao afirmarem que "ações de governos, entidades privadas e de ensino e pesquisa começam a colocar as atividades criativas como importantes para o desenvolvimento regional e nacional".

Sendo abordada pela primeira vez na Austrália em 1994 e ganhando destaque ao ser utilizada pelo governo inglês em sua estratégia de política macroeconômica em 1997 (GOLDENSTEIN, 2016), uma noção de Economia Criativa, e por consequência de Indústria Criativa (de viés mais prático), vem sendo discutida e utilizada cada vez mais por países que buscam estratégias frente à crise econômica. Tendo seu debate se iniciado no Brasil entre 2006 e 2007 (GOLDENSTEIN, 2016), sua abordagem estratégica foi primeiramente instituída com a criação da Secretaria de Economia Criativa, em 2011, pelo governo brasileiro (DE MARCHI, 2014).

\footnotetext{
${ }^{1}$ Universidade Federal de Mato Grosso do Sul (UFMS), Campo Grande, Mato Grosso do Sul, Brasil.
} 
Entendida preliminarmente como "setores cuja origem de geração de valor econômico está na criatividade, no conhecimento e no talento individual e coletivo que possuem potencial para criação de riqueza e empregos através da geração e exploração de ativos criativos" (PACHECO, 2016, p. 14), a pesquisa que relaciona Economia Criativa e políticas públicas ainda se apresenta de maneira tímida e incipiente, como apontado através de breve pesquisa do termo "economia criativa" na base de dados SciELO - Scientific Electronic Library Online, onde podem ser encontrados apenas 20 artigos sobre o tema.

Para além do número reduzido de pesquisas, o estudo do tema se torna relevante não somente pelo amplo debate já realizado fora do país, como também pelo demonstrado no levantamento realizado pela Federação das Indústrias do Estado do Rio de Janeiro (FIRJAN, 2016), o qual apontou que as indústrias criativas geraram uma riqueza de $R \$ 155,6$ bilhões para o país em 2015, correspondendo a um aumento de 2,56\% para 2,64\%, de 2013 a 2015, em participação dos setores de Economia Criativa no PIB brasileiro.

Além disso, o atual ministro da Cultura, Sérgio Sá Leitão, apontou recentemente em entrevista concedida à Folha de São Paulo que o desenvolvimento da Economia Criativa é sua prioridade e que, em sua gestão, tem como meta "[...] ao fim de 2018, deixar o ministério dotado de um conjunto de diretrizes, políticas e ações voltadas à economia criativa" (MUNIZ, 2017, p. 1). Neste contexto, entender o desenvolvimento e a institucionalização da Economia Criativa no Brasil torna-se fundamental para contribuir com e para este cenário.

Assim, este trabalho busca responder a seguinte pergunta: qual o estado da institucionalização da Economia Criativa como política pública no estado de Mato Grosso do Sul? De maneira mais detalhada, esta pesquisa procura entender qual tem sido o papel do governo (sobretudo em âmbito estadual) no processo de introdução e difusão da Economia Criativa nesse estado, que tem visto grande crescimento de seu PIB ao longo dos últimos anos, mas que, no levantamento apresentado pela Federação das Indústrias do Estado do Rio de Janeiro (FIRJAN, 2016), ainda possui o seu PIB Criativo estimado em 1,3\% (2015), comparado a São Paulo, com 3,9\% para o mesmo período, ou seja, número ainda relativamente baixo. Com este enfoque, espera-se ter um panorama das principais iniciativas que fomentem a Economia Criativa no estado.

Para tanto, o artigo foi dividido em 4 seções além da introdução: na seção 2, são apresentados os constructos teóricos sobre o tema central deste artigo - Economia Criativa; na seção 3 , é apresentada a metodologia utilizada no estudo; a 4a seção destina-se a realizar uma discussão sobre os dados levantados. Por fim, na última seção, são apresentadas considerações sobre o trabalho. Espera-se, dessa forma, que este artigo possa contribuir com informações para um primeiro levantamento da Economia Criativa como política pública no estado, bem como propor novos passos para sua consolidação.

\section{FUNDAMENTOS TEÓRICOS}

Como mencionado acima, a ideia de Economia Criativa começou a ser delineada na Austrália, em 30 de outubro de 1994, com o lançamento pelo então primeiro-ministro australiano Paul Keating do Creative nation: Commonwealth cultural policy, um plano de políticas públicas que previa o investimento de um equivalente a 250 milhões de dólares em atividades ligadas à cultura e à criatividade. Ainda que o estabelecimento de políticas culturais não seja uma novidade, já que, por exemplo, poderia se recordar da parceria entre Winston Churchill e John Maynard Keynes no Reino Unido durante a Segunda Guerra Mundial (SINCLAIR, 1995) ou da gestão de 
Mário de Andrade no Departamento de Cultura do município de São Paulo (PANCHERI, 2012), o diferencial do projeto australiano estava justamente em prever o agenciamento de instâncias mais amplas que a mera produção artística e cultural, como se pode exemplificar bem com o seguinte excerto do relatório:

Esta política cultural também é uma política econômica. A cultura cria riqueza. Em termos gerais, nossas indústrias culturais geram 13 bilhões de dólares por ano. Cultura emprega. Cerca de 336.000 australianos são empregados em indústrias relacionadas à cultura. A cultura agrega valor, faz um contributo essencial para inovação, marketing e design. É um emblema da nossa indústria. O nível de nossa criatividade determina substancialmente nossa capacidade de adaptação a novos imperativos econômicos. É uma exportação valiosa em si e um acompanhamento essencial para a exportação de outras commodities. Atrai turistas e estudantes. É essencial para o nosso sucesso econômico. (KEATING, 1994, p. 1, tradução nossa). ${ }^{2}$

Dessa maneira, o primeiro-ministro Keating vislumbrava pela primeira vez uma aplicação positiva das atividades humanas que lidam com a criatividade em sua influência não apenas na constituição da cultura de uma nação, mas na própria estruturação econômica e social desse povo. Nesse sentido, o vetor de responsabilidade social se inverte entre as ideias de Economia Criativa e Indústria Cultural, de forma que a primeira parece enfatizar uma melhor distribuição econômica, naquilo que a segunda parece agenciar enquanto mera clientela, ao menos na acepção adorniana.

Entretanto, se Foucault estava certo, as palavras significam coisas, e a reflexão acerca do impacto econômico de tais políticas públicas pode escorregar facilmente para ideologizações, que pouco contribuem para o estabelecimento e para a proposição de atitudes que de fato lidem com a totalidade dessa realidade social. A afirmação do primeiro-ministro ecoa fundo quando declara que "o nível de nossa criatividade determina substancialmente nossa capacidade de adaptação a novos imperativos econômicos", sobretudo em contextos como o brasileiro, em que a crise é matéria de especulação financeira e política. Por essa razão é importante que se entenda a Economia Criativa não apenas como uma boa ideia, mas como um conceito necessário para a administração pública contemporânea.

Falar em conceito demanda não apenas cunhar uma nova terminologia, como os jargões organizacionais que vêm e vão dentro dos contextos da administração, mas estabelecer componentes sólidos que orientem a reflexão e a prática humana. Como pensam Deleuze e Guattari (2010, p. 34-7), o conceito é um conjunto de componentes que se encarnam em um corpo material, não como soma desses componentes, mas como trajetória de seus movimentos particulares. Sendo assim, definir um conceito está mais próximo do estabelecimento de uma órbita do que da escrita de um verbete. Conceitos conectam ideias, pessoas, enfim, corpos. Portanto um conceito deve ser capaz de operar movimentos que sem ele permaneceriam em uma névoa de virtuais sem operação possível. Conceitos são acontecimentos, logo, necessitam de agentes.

Dentro da administração pública, o conceito de Economia Criativa propõe uma articulação entre agentes públicos que, de outra maneira, permaneceriam sem instrumental adequado para

\footnotetext{
${ }^{2}$ No original: This cultural policy is also an economic policy. Culture creates wealth. Broadly defined, our cultural industries generate 13 billion dollars a year. Culture employs. Around 336,000 Australians are employed in culturerelated industries. Culture adds value, it makes an essential contribution to innovation, marketing and design. It is a badge of our industry. The level of our creativity substantially determines our ability to adapt to new economic imperatives. It is a valuable export in itself and an essential accompaniment to the export of other commodities. It attracts tourists and students. It is essential to our economic success.
} 
refletirem e praticarem a gestão das instâncias envolvidas no fazer criativo. Era mais próxima dessa intenção que John Howkins (2001) propusera pioneiramente o conceito de Economia Criativa, entendendo-o como um mecanismo que conectava ações criativas a sua rentabilidade econômica, incluindo nisso a rede de relações financeiras que dela provinha. Contudo, a limitação da proposição de Howkins era considerar não o ato criativo, mas exclusivamente o produto desse ato enquanto objeto passível de valoração econômica. Ora, ações humanas configuram-se como tais pelo seu processo, e não pelo objeto resultante desse processo; dessa maneira, a criatividade humana está presente não apenas na objetificação de uma ação, mas em toda sua dinâmica própria (TEIXEIRA; FERRAZ, 2017).

Desse modo, é fundamental para a conceituação da Economia Criativa uma abordagem que não objetifique o conceito, mas o situe em uma imanência existencial que considere a rede de relações humanas enquanto movimentos, e não apenas fixações objetivas e classificáveis. Como Deleuze (1987) sugerira finalmente, o ato criativo é por si mesmo um ato de resistência: uma resistência à morte. A letargia, o mal do século XX segundo Dorothy Sayers (1941), é o oposto, a manutenção das coisas em seu movimento próprio de declínio e decomposição. A criação, por outro lado, é a força que gera e que nessa força inclusive produz; mas o produto não é a criação. Portanto uma acepção adequada de Economia Criativa deve alçar como prioridade o fator humano que está incluído em sua prática; terminologias tentam ocultar essas necessidades sob diferentes alcunhas e, com isso, originam apenas abordagem difusas e, consequentemente, políticas públicas que ignoram as forças criativas de uma população, resultando em sua própria e derradeira ineficácia.

É nesse sentido que Schlesinger (2016) apresenta o risco de a Economia Criativa se tornar apenas um tropo, uma figura de linguagem que outorga autoridade àquele que a pronuncia, mas que finalmente não produz sentido algum. Dentro dessa acepção, o conceito se torna meramente um rótulo de mercado que resulta em boas vendas para uma governança neoliberal que visa apenas ao capital e, no caso da administração pública, ao capital financeiro e eleitoral. Nesse movimento, atividades aparentemente inócuas, ainda que parte da identidade de uma sociedade, são ignoradas e mantidas à margem do espectro de possibilidades de investimento público. A questão final está, portanto, posta: quem define o criativo no homem, suas ações em ser-no-mundo ou o mercado?

Dessa maneira, adota-se aqui uma acepção de Economia Criativa mensurada não apenas por sua geração de renda e emprego, mas também pela sensibilidade em enxergar as particularidades regionais e culturais de uma sociedade, não aplicando cegamente uma lógica mercantilista do lucro a qualquer custo. A leitura do estado atual da Economia Criativa no estado de Mato Grosso do Sul deve, via de regra, considerar sua multiculturalidade e outros tantos atributos da cultura que levam a criatividade de seu povo muito além da simples produção ornamental. Assim, o conceito assume seu papel fundamental para o planejamento e a implementação de políticas públicas consistentes e efetivas, além do mero marketing social ou do jargão empreendedor.

\section{PROCEDIMENTOS METODOLÓGICOS}

Uma vez que o objetivo deste estudo é analisar o processo de institucionalização da Economia Criativa em Mato Grosso do Sul enquanto política pública, é possível classificá-lo como descritivo, o qual, segundo Neuman (2014), é definido por "pintar uma imagem" detalhada sobre 
o que está sendo observado, por meio de números ou palavras, podendo ser realizado através de documentação de processos e mecanismos causais ou relatando o contexto de uma situação.

Por se tratar de um estudo qualitativo, uma vez que será realizada a interpretação dos dados encontrados, a estratégia utilizada foi a pesquisa documental, em que foram analisados os documentos disponíveis no Diário Oficial do estado de Mato Grosso do Sul. Godoy (1995, p. 21 e 23) salienta que a pesquisa documental se constitui no "exame de materiais de natureza diversa, que ainda não receberam tratamento analítico, ou que podem ser reexaminados, buscando-se novas e/ou interpretações complementares" e é descrita pela "escolha dos documentos, o acesso a eles e sua análise".

As análises foram restringidas aos dados disponíveis em formato on-line no período de 2012 a 2017, em que se procurou por documentos que mencionassem em seus conteúdos o termo "Economia Criativa". Através das análises, buscou-se definir se existe e/ou como se deu a institucionalização da Economia Criativa como política pública no estado de Mato Grosso do Sul, bem como definir se há e quais são os recursos disponíveis para o seu fomento e implementação.

\section{ANÁLISE E DISCUSSÃO}

A primeira vez que o termo Economia Criativa aparece nos documentos oficiais disponíveis no Diário Oficial do estado de Mato Grosso do Sul é em 19 de agosto de 2013 através da Portaria de n. 44, em que a Economia Criativa aparece como uma das temáticas da III Conferência Estadual de Cultura de Mato Grosso do Sul, a ser discutida como uma estratégia de desenvolvimento sustentável (MATO GROSSO DO SUL, 2013). Embora não se trate ainda de sua institucionalização naquela época, a sua escolha como uma das temáticas do evento corrobora com um certo interesse do governo do estado pela Economia Criativa.

Um importante marco para a institucionalização da Economia Criativa no estado ocorre, de fato, quase dois anos depois da III Conferência, quando, através do Decreto n. 14.169, de 27 de abril de 2015, é estabelecida a Superintendência de Economia Criativa na estrutura básica da Secretaria de Estado de Cultura, Turismo, Empreendedorismo e Inovação (SECTEI). Sendo um dos "órgãos de direção superior e assessoramento" do Secretário de Cultura, Turismo, Empreendedorismo e Inovação, a Superintendência foi estabelecida com onze finalidades, sendo elas:

I- fomentar a economia criativa do Estado de Mato Grosso do Sul, acompanhar, fortalecer e potencializar as iniciativas de economia criativa no âmbito estadual, com o objetivo de aumentar sua capacidade de gerar trabalho e renda; II- formular, implementar e acompanhar as políticas públicas de incentivo aos negócios ligados ao setor de economia criativa, compatibilizando o desenvolvimento socioeconômico com a perspectiva de sustentabilidade, inclusão social e de valorização da diversidade cultural do Estado; III- elaborar um Plano Estadual de Economia Criativa e estimular a criação e/ou o enquadramento de instrumentos legais no campo da economia criativa; IV- planejar, coordenar e estabelecer parcerias e convênios de cooperação técnica, inclusive aqueles que envolvam transferência de recursos financeiros no âmbito de sua área de atuação, com instituições regionais, nacionais e internacionais; $V$ - mapear a economia criativa no Estado de Mato Grosso do Sul, objetivando identificar vocações e oportunidades de desenvolvimento local e regional; VI - promover a interação entre os órgãos que compõem a SECTEI, como também com os demais órgãos do Governo do Estado, fornecendo subsídios que permitam o melhor desenvolvimento das atividades, a interação institucional e a inserção da temática da economia criativa em seus âmbitos de atuação; VII 
- constituir comitês para a interação entre as divisões da estrutura organizacional da SECTEI, criar grupos de trabalho, comissões especiais em caráter permanente ou transitório, para fins de estudos ou de execução de atividades de promoção da economia criativa; VIII- realizar formação continuada na área de economia criativa por meio de fóruns, congressos, oficinas, palestras, entre outros; IX- planejar, propor, formular e estimular a implementação de políticas públicas para os setores criativos, visando ao fortalecimento de suas cadeias produtivas, em especial os micros e pequenos empreendimentos criativos; X-representar o Estado de Mato Grosso do Sul em eventos regionais, nacionais e internacionais pertinentes aos setores e ao desenvolvimento da economia criativa, em articulação com a SECTEI; XI- atuar em parceria com a sociedade civil e as entidades de mercado dotadas de responsabilidade social. (MATO GROSSO DO SUL, 2015c).

Menos de um mês após o estabelecimento da Superintendência, em 12 de maio de 2015 há menção à dispensa de licitação para contratação de Ana Carla Fonseca Reis, economista e especialista internacional em Economia Criativa, a fim de que esta realizasse a palestra "Economia Criativa: Traduzindo em Miúdos", através do Projeto Apoio à Implantação dos Sistemas Municipais de Cultura (MATO GROSSO DO SUL, 2015b). Mais uma vez, fica claro o interesse do governo em debater e trazer à tona a temática para o estado de Mato Grosso do Sul. Realizada no dia 13 de maio de 2015, a palestra de Ana Carla, além de sanar dúvidas sobre a temática, incentivou o trabalho já realizado pelo governo do estado, pelo fato de a especialista considerar inovadora a iniciativa de serem trabalhadas conjuntamente as pastas de Cultura, Turismo e Empreendedorismo e Inovação (FUNDAÇÃO DE CULTURA, 2015).

Quanto ao fomento da Economia Criativa no estado, é notável o empenho do governo em manter o tema ativo nos principais eventos, como a contratação de palestrantes sobre Economia Criativa para o "Festival América do Sul - Criando Mecanismos para sua Implementação", nos anos de 2015 e 2016, e também com a abertura da Chamada Pública 001/2017 para a seleção de expositores para o pavilhão do "2o MS Mostra MS - Espaço Economia Criativa - SECC/MS - 14으 Festival América do Sul Pantanal 2017", que buscou fomentar, acompanhar, fortalecer e potencializar as iniciativas de economia criativa selecionadas em 2017 (MATO GROSSO DO SUL, 2017d). Destaca-se ainda a a provação, em novembro de 2017, de $R \$ 20.000,00$ para a realização do projeto "E-Criativo: Plataforma de Documentação e Memória da Economia Criativa de MS" (MATO GROSSO DO SUL, 2017b).

Também cabe destacar a abertura de outras duas chamadas públicas, a Chamada Pública SECTEI n. 02/2015³ e a Chamada Pública SECTEI n. 03/2016, no valor de R\$250.000,00 (duzentos e cinquenta mil reais) cada uma, referentes à concessão de custeio e capital de apoio ao desenvolvimento de projetos de Economia Criativa, visando ao apoio a Empreendedores da Economia Criativa Sul-Mato-Grossense nos anos de 2015 e 2016. O valor do aporte financeiro de ambas as Chamadas não foi alterado, o que antecipa o fato de que posteriormente a primeira seria anulada, permanecendo apenas a segunda em vigência. Entretanto, há diferenças significativas entre as duas chamadas, como o enquadramento dos valores dos projetos, sendo concedidos recursos para apoio de cinco projetos individuais de até $\mathrm{R} \$ 10.000,00$ e dez projetos coletivos de até $R \$ 20.000,00$, na Chamada n. 02/2015, e, na Chamada n. 03/2016, apoio de dez projetos de $\mathrm{R} \$ 20.000,00$ e um projeto no valor de R\$50.000,00 (MATO GROSSO DO SUL, 2015a; 2016a).

Ressalta-se também a diferença entre os objetivos específicos das chamadas, já que na primeira são destacados seis pontos bastante distintos entre si, como "avaliar e acompanhar o

\footnotetext{
${ }^{3}$ Republicada por incorreção em 6 de janeiro de 2016, por meio do Diário Oficial de Mato Grosso do Sul, n. 9.078.
} 
desenvolvimento e a implementação dos projetos e seus impactos" e "estimular a criação do Observatório de Economia Criativa no Estado de Mato Grosso do Sul" (MATO GROSSO DO SUL, 2015a, p. 30), parecendo mais com as intenções da Superintendência de Economia Criativa do que com os objetivos específicos de uma chamada, em contraponto ao objetivo específico sucinto da segunda chamada, de "estimular, valorizar e fomentar empreendimentos criativos no Estado de Mato Grosso do Sul, tendo em vista o desenvolvimento social, cultural, turístico, econômico e artístico, bem como a inovação, a sustentabilidade e a geração de renda dos empreendedores individuais ou grupos sociais" (MATO GROSSO DO SUL, 2016a, p. 35).

Ainda sobre as chamadas, ressalta-se a diferença na definição utilizada para Economia Criativa mesmo estas tendo sido publicadas em um curto intervalo de tempo (oito meses), o que talvez demonstre a necessidade de um maior aprofundamento e entendimento sobre o conceito de Economia Criativa por parte da Superintendência de Economia Criativa. Na primeira chamada, a Economia Criativa é entendida como:

[...] um conjunto de atividades culturais, econômicas e de gestão de negócios que se originam no conhecimento, na criatividade, no capital intelectual individual ou coletivo focadas em processos, produções de bens e serviços para a geração de trabalho e renda. (MATO GROSSO DO SUL, 2015a, p. 30).

Já na segunda chamada a definição passa a ser:

[...] [...] as dinâmicas culturais, sociais e econômicas construídas a partir do ciclo de criação, produção, distribuição/circulação/difusão e consumo/fruição de bens e serviços oriundos dos setores criativos, cujas atividades produtivas têm como processo principal um ato criativo gerador de valor simbólico, elemento central da formação do preço, e que resulta em produção de riqueza cultural e econômica. (MATO GROSSO DO SUL, 2016a, p. 35).

Contudo, é a partir da Lei n. 4.806, de 21 de dezembro de 2015, que é instituído o Plano Plurianual (PPA) para o período de 2016/2019, em que a Economia Criativa começa a ser de fato institucionalizada como política pública no estado. O Plano, além de ressaltar que a Economia Criativa tem sido considerada por diversas organizações internacionais como um "eixo estratégico de desenvolvimento para sociedades contemporâneas", destaca ainda que os estudos sobre o tema são incipientes tanto na academia quanto nos "setores programáticos da atividade criativa no Estado do Mato Grosso do Sul" (MATO GROSSO DO SUL, 2015d, p. 70).

Para tanto, cria-se o Programa de Economia Criativa visando "identificar, mapear e monitorar áreas estratégicas da Economia Criativa, a fim de fomentar ações e projetos dos setores criativos identificados e mapeados"; fortalecer o setor e apontar novos caminhos para a política pública através do "primeiro Plano Estadual de Economia Criativa" e; "[...] promover o desenvolvimento e a profissionalização de setores criativos com potencialidades econômicas, capazes de gerar oportunidades de emprego e renda, bem como o desenvolvimento dos 79 municípios do Estado e suas 11 regiões" (MATO GROSSO DO SUL, 2015d, p. 70).

Além de definir quatro ações dentro do Programa de Economia Criativa, sendo elas: i) "Articular visando o fomento e o apoio técnico para os setores da Economia Criativa"; ii) "Promover a capacitação dos setores da Economia Criativa", iii) "Articular e implementar marcos legais para desenvolvimento da Economia Criativa"; iv) "Identificar, diagnosticar e acompanhar os setores da Economia Criativa", o Plano também estipula a criação de um Observatório de Economia Criativa, vinculado ao Programa Ciência, Tecnologia e Inovação, além de "Instituir os Sistemas Estadual e Municipais de Cultura, Turismo, Economia Criativa, Ciência, Tecnologia e Inovação" e 
"Implementar atividades de Cultura, Turismo, Economia Criativa, Ciência, Tecnologia e Inovação nos municípios", através do Programa MS Cultura (MATO GROSSO DO SUL, 2015d, p. 343-4).

A existência de orçamento específico para as ações de Economia Criativa, tanto estipuladas no PPA quanto através da Lei de Orçamento Anual (LOA) de 2016 e 2017 (MATO GROSSO DO SUL, 2015e; 2016c), também corrobora com a afirmação da institucionalização da Economia Criativa como política pública no estado. Contudo, cabe observar que em menos de um ano de execução, através da Lei n. 4.975 de 29 de dezembro de 2016, que aprova a primeira revisão do Plano Plurianual para o período 2016/2019, o orçamento para as ações de Economia Criativa foi reduzido drasticamente, como podemos observar nas tabelas a seguir:

Tabela 1 - Orçamento previsto para Ações de Economia Criativa

\begin{tabular}{|c|c|c|c|c|}
\hline \multicolumn{5}{|c|}{ PPA 2016-2019 } \\
\hline Código & Título & 2016 & $2017 / 2019$ & Total \\
\hline 2023 & $\begin{array}{l}\text { Programa de Ciência, Tecnologia e } \\
\text { Inovação }\end{array}$ & & & \\
\hline 2639 & $\begin{array}{l}\text { Criar Observatório de Economia Criativa } \\
\text { para agregar e fomentar projetos de } \\
\text { ambientes inovadores e tecnologias } \\
\text { sociais do Estado. }\end{array}$ & $6.000 .000,00$ & $19.891 .000,00$ & $25.891 .000,00$ \\
\hline 2025 & Programa MS Cultura & & & \\
\hline 1581 & $\begin{array}{c}\text { Instituir os Sistemas Estadual e } \\
\text { Municipais de Cultura, Turismo, } \\
\text { Economia Criativa, Ciência, Tecnologia e } \\
\text { Inovação. }\end{array}$ & $245.000,00$ & $3.025 .000,00$ & $3.270 .000,00$ \\
\hline 2581 & $\begin{array}{l}\text { Implementar atividades de Cultura, } \\
\text { Turismo, Economia Criativa, Ciência, } \\
\text { Tecnologia e Inovação nos municípios. }\end{array}$ & $3.500 .000,00$ & $43.000 .000,00$ & $46.500 .000,00$ \\
\hline 2026 & Programa Economia Criativa & & & \\
\hline 2582 & $\begin{array}{c}\text { Articular visando o fomento e o apoio } \\
\text { técnico para os setores da Economia } \\
\text { Criativa. }\end{array}$ & $437.500,00$ & $5.362 .500,00$ & $5.800 .000,00$ \\
\hline 2583 & $\begin{array}{l}\text { Promover a capacitação dos setores da } \\
\text { Economia Criativa. }\end{array}$ & $153.000,00$ & $1.874 .000,00$ & $2.027 .000,00$ \\
\hline 2584 & $\begin{array}{l}\text { Articular e implementar marcos legais } \\
\text { para desenvolvimento da Economia } \\
\text { Criativa. }\end{array}$ & $105.000,00$ & $1.255 .000,00$ & $1.360 .000,00$ \\
\hline 2585 & $\begin{array}{l}\text { Identificar, diagnosticar e acompanhar os } \\
\text { setores da Economia Criativa. }\end{array}$ & $157.500,00$ & $1.952 .500,00$ & $2.110 .000,00$ \\
\hline Total & $\begin{array}{l}\text { Ações que contemplem a Economia } \\
\text { Criativa }\end{array}$ & $10.598 .000,00$ & $76.360 .000,00$ & $86.958 .000,00$ \\
\hline
\end{tabular}

Fonte: Elaboração própria, baseado no Plano Plurianual para o período de 2016-2019 (MATO GROSSO DO SUL, 2015d). 
Tabela 2 - Orçamento previsto para Ações de Economia Criativa

\begin{tabular}{|c|c|c|c|c|}
\hline \multicolumn{5}{|c|}{ PPA 2016-2019 - primeira revisão } \\
\hline Código & Título & 2017 & $2018 / 2019$ & Total \\
\hline 2023 & $\begin{array}{l}\text { Programa de Ciência, Tecnologia e } \\
\text { Inovação }\end{array}$ & & & \\
\hline 2639 & $\begin{array}{l}\text { Criar Observatório de Economia Criativa } \\
\text { para agregar e fomentar projetos de } \\
\text { ambientes inovadores e tecnologias } \\
\text { sociais do Estado. }\end{array}$ & $2.000 .000,00$ & $4.573 .200,00$ & $6.573 .200,00$ \\
\hline 2025 & Programa MS Cultura & & & \\
\hline 1581 & $\begin{array}{c}\text { Instituir os Sistemas Estadual e } \\
\text { Municipais de Cultura, Turismo, } \\
\text { Economia Criativa, Ciência, Tecnologia e } \\
\text { Inovação. }\end{array}$ & 200,00 & 800,00 & $1.000,00$ \\
\hline 2581 & $\begin{array}{l}\text { Implementar atividades de Cultura, } \\
\text { Turismo, Economia Criativa, Ciência, } \\
\text { Tecnologia e Inovação nos municípios. }\end{array}$ & 200,00 & 800,00 & $1.000,00$ \\
\hline 2026 & Programa Economia Criativa & & & \\
\hline 2582 & $\begin{array}{c}\text { Articular visando o fomento e o apoio } \\
\text { técnico para os setores da Economia } \\
\text { Criativa. }\end{array}$ & 200,00 & 800,00 & $1.000,00$ \\
\hline 2583 & $\begin{array}{l}\text { Promover a capacitação dos setores da } \\
\text { Economia Criativa. }\end{array}$ & 200,00 & 800,00 & $1.000,00$ \\
\hline 2584 & $\begin{array}{c}\text { Articular e implementar marcos legais } \\
\text { para desenvolvimento da Economia } \\
\text { Criativa. }\end{array}$ & 200,00 & 800,00 & $1.000,00$ \\
\hline 2585 & $\begin{array}{l}\text { Identificar, diagnosticar e acompanhar } \\
\text { os setores da Economia Criativa. }\end{array}$ & 200,00 & 800,00 & $1.000,00$ \\
\hline Total & $\begin{array}{c}\text { Ações que contemplem a Economia } \\
\text { Criativa }\end{array}$ & $2.001 .200,00$ & $4.578 .000,00$ & $6.579 .200,00$ \\
\hline
\end{tabular}

Fonte: Elaboração própria, baseado na revisão do Plano Plurianual para o período de 2016-2019 (MATO GROSSO DO SUL, 2016c).

De uma verba total de $\mathrm{R} \$ 86.958 .000,00$ na primeira versão do Plano, a somatória passa a $\mathrm{R} \$$ 6.579.200,00 na primeira revisão do PPA, trazendo também irrisórios valores, de R\$ 200,00 e $\mathrm{R} \$ \mathbf{8 0 0}, 00$, para a execução de ações que um ano antes estavam na casa dos milhares. Embora conclusões sejam precipitadas nesse primeiro momento, a brusca alteração de valores destinados às ações de Economia Criativa no estado pode significar certo desinteresse do governo em dar prosseguimento às ações desta pasta ou mesmo uma intenção de descontinuidade das ações planejadas, fato que conflita com as ações de fomento à temática ainda em vigor em 2017, como discutidas acima.

Outros marcos que impactam diretamente a Economia Criativa no estado são: i) a reorganização da Estrutura Básica do Poder Executivo do estado de Mato Grosso do Sul, por meio da 
Lei n. 4.982, de 14 de março de 2017, em que a Secretaria deixa de ser "Secretaria de Estado de Cultura, Turismo, Empreendedorismo e Inovação (SECTEI) e passa a ser "Secretaria de Estado de Cultura e Cidadania (SECC)", deixando então a transversalidade da Cultura com o Turismo, Empreendedorismo e Inovação (MATO GROSSO DO SUL, 2017c) e; ii) a reorganização da SECC, através do Decreto n. 14.692, de 21 de março de 2017, em que a Economia Criativa deixa de ser uma Superintendência e passa a ser uma Coordenadoria subordinada à Superintendência de Cultura (MATO GROSSO DO SUL, 2017a). Embora mantida com as mesmas 11 finalidades estipuladas em 2015, a mudança de superintendência para coordenadoria pode significar um menor grau de autonomia para as ações de Economia Criativa e até mesmo uma redução de orçamento para esta última, como já vislumbrado no parágrafo anterior.

\section{CONSIDERAÇÕES FINAIS}

A análise dos documentos demostra que o governo do estado tem se empenhado em fomentar a Economia Criativa por meio de eventos e editais, no entanto, sua institucionalização como política pública ainda parece acontecer de maneira tímida, uma vez que se encontra apenas no Planejamento Plurianual de 2016 a 2019 e nas Leis Orçamentárias de 2016 e 2017. De fato, como previsto nesse Planejamento, a criação de um Plano Estadual de Economia Criativa resultaria na força necessária para sua consolidação, fato ainda distante.

Dois pontos chamam a atenção para possíveis dificuldades no futuro quanto à Economia Criativa no estado. O primeiro é o rebaixamento da Superintendência de Economia Criativa para a categoria de Coordenação, o que pode significar uma perda de autonomia de suas ações. Em segundo lugar, a brusca redução de orçamento na revisão do PPA de 2016 a 2019, o que também pode demonstrar um desinteresse do governo em outorgar continuidade às ações já iniciadas.

Nesse cenário, é importante que a Coordenadoria de Economia Criativa passe a contar com parcerias para conseguir cumprir os objetivos definidos no Plano até 2019, primeiramente com os governos municipais, mas também com entidades como a Universidade Federal de Mato Grosso do Sul, que poderia auxiliar no mapeamento da Economia Criativa no estado, na elaboração do plano de Economia Criativa, na avaliação das iniciativas já realizadas, dentre outras colaborações. Destaca-se também o papel do SEBRAE-MS, que desde 2016 tem como uma de suas prioridades estratégicas "apoiar o desenvolvimento do turismo e cultura, fortalecendo a economia criativa como atividade econômica sustentável". Ainda sobre o SEBRAE, tal parceria seria uma opção para suprir a redução de orçamento, uma vez que em 2016 foram executados pelo SEBRAE-MS o montante de $\mathrm{R} \$ 1.473 .627,00$ para a estratégia acima descrita (SEBRAE-MS, 2017).

A implementação de políticas públicas em Economia Criativa é um passo fundamental para situar o estado em posição minimamente adequada ao recebimento de investimentos nacionais e internacionais que, de outra maneira, permanecerão distantes dos cofres públicos. Como apresentam Hanania e Vlassis (2017), uma política sólida nesse setor é critério central nas avaliações de governança da Organização das Nações Unidas (ONU), o que tem sensibilizado os países BRICS (grupo formado por Brasil, Rússia, Índia, China e África do Sul) a concentrarem esforços em sua execução, de maneira a não dependerem unicamente de um mercado criativo internacional que resulta em um volumoso deficit na balança comercial.

Finalmente, o estado necessita urgentemente se atentar para uma definição clara do conceito de Economia Criativa, e não situá-lo convenientemente em ações pontuais, já que 
sua aplicação tem sido alçada à posição central na apresentação de projetos que objetivem a captação de recursos via Lei Rouanet, sobretudo a partir da nova Instrução Normativa n. 4, de 30 de novembro de 2017, que exige que projetos com orçamento acima dos 3 milhões de reais apresentem um estudo de impacto econômico, ação essa motivada por um interesse estratégico de "mudar a imagem do setor cultural, por meio de dados que afirmem o valor da economia criativa e as externalidades positivas, na geração de emprego, renda e PIB". Dessa maneira, o Ministério espera o "reconhecimento da cultura como geradora de valor econômico e social" e a "criação de indicadores e melhores práticas para a execução de projetos culturais, dentro do conceito da economia criativa" (MINISTÉRIO DA CULTURA, 2017).

Para a proposição de ações efetivas quanto ao fomento da Economia Criativa, é imprescindível e tardio o mapeamento das ações já desenvolvidas e dos potenciais de desenvolvimento de cada um dos 79 municípios do estado, além da articulação e precisa delimitação de todos os agentes públicos e privados envolvidos na constituição dessa política. Dessa maneira, espera-se minimamente que o estado se adeque ao panorama nacional, encontrando sua vocação própria, que resultaria em uma diversificação muito importante de sua matriz econômica, que finalmente denotaria um aumento de sua segurança financeira e da distribuição não apenas de renda, mas de seus bens culturais, o que manifestaria uma preocupação séria do estado com o desenvolvimento humano de sua população.

\section{REFERÊNCIAS}

DALLA COSTA, Armando João; SOUZA-SANTOS, E. R. Economia criativa no Brasil: quadro atual, desafios e perspectivas. Economia \& Tecnologia (UFPR), Curitiba, ano 7, v. 27, p. 151-9, out./dez. 2011.

DELEUZE, Gilles. Qu'est-ce que l'acte de création? Conferência dada em 17 de maio de 1987. Disponível em: http://www.lepeuplequimanque.org/acte-de-creation-gilles-deleuze.html. Acesso em: 30 out. 2017.

DELEUZE, Gilles; GUATTARI, Felix. O que é a filosofia? São Paulo: Editora 34, 2010.

DE MARCHI, Leonardo. Análise do Plano da Secretaria da Economia Criativa e as transformações na relação entre Estado e cultura no Brasil. Intercom: Revista Brasileira de Ciências da Comunicação, São Paulo, v. 37, n. 1, p. 193-215, jun. 2014. Disponível em: http://www.scielo.br/scielo.php?script=sci_arttext\&pid=S180958442014000100010\&Ing=en\&nrm=iso. Acesso em: 11 set. 2017.

FEDERAÇÃO DAS INDÚSTRIAS DO ESTADO DO RIO DE JANEIRO (FIRJAN). Mapeamento da Indústria Criativa no Brasil. Rio de Janeiro: Firjan, 2016. Disponível em http://www.firjan.com.br/EconomiaCriativa/pages/ default.aspx. Acesso em: 10 dez. 2017.

FUNDAÇÃO DE CULTURA. Políticas Públicas. Conferencista de Economia Criativa incentiva a transversalidade das pastas da SECTEI. 2015. Disponível em: http://www.fundacaodecultura.ms.gov.br/conferencista-deeconomia-criativa-incentiva-a-transversalidade-das-pastas-da-sectei/. Acesso em: 10 dez. 2017.

GODOY, Arilda Schmidt. Pesquisa qualitativa: tipos fundamentais. Revista de Administração de Empresas, São Paulo, SP, v. 35, n. 3, p. 20-29, maio/jun. 1995. Disponível em: http://www.spell.org.br/documentos/ ver/12736/pesquisa-qualitativa---tipos-fundamentais. Acesso em: 3 set. 2017.

GOLDENSTEIN, Lídia. Por que economia criativa? In: SISTEMA FIRJAN. Mapeamento da Indústria Criativa. Rio de Janeiro: Firjan, 2016. Disponível em http://www.firjan.com.br/EconomiaCriativa/pages/default. aspx. Acesso em: 11 set. 2017. 
HANANIA, Lilian Richieri; VLASSIS, Antonio. For a BRICS agenda on culture and the Creative Economy. In: NEUWIRTH, R. J. et al. (Org.). The BRICS-Lawyers' Guide to Global Cooperation. Cambridge: Cambridge University Press, 2017.

HOWKINS, John. The Creative Economy: how people make money from ideas. Londres: Penguin Books, 2001.

KEATING, Paul. Creative Nation: commonwealth cultural policy. Relatório lançado em 30 de outubro de 1994. Disponível em: http://pandora.nla.gov.au/pan/21336/20031011-0000/www.nla.gov.au/creative. nation/contents.html. Acesso em: 10 dez. 2017.

MATO GROSSO DO SUL (MS). Decreto n. 14.692, de 21 de março de 2017. Reorganiza a estrutura básica da Secretaria de Estado de Cultura e Cidadania (SECC), e dá outras providências. 2017a. Disponível em: http://www.spdo.ms.gov.br/diariodoe/Index/Download/D09374_22_03_2017. Acesso em: 9 dez. 2017.

MATO GROSSO DO SUL (MS). Extrato do Termo de Outorga n. 27780/2017. Diário Oficial n. 9.540, p. 09 do dia 27 de novembro de 2017. 2017b. Disponível em: http://www.spdo.ms.gov.br/diariodoe/Index/ Download/DO9540_27_11_2017. Acesso em: 9 dez. 2017.

MATO GROSSO DO SUL (MS). Lei n. 4.982, de 14 de março de 2017. Altera e acrescenta dispositivos à Lei n. 4.640, de 24 de dezembro de 2014, que reorganiza a Estrutura Básica do Poder Executivo do Estado de Mato Grosso do Sul, e dá outras providências. 2017c. Disponível em: http://www.spdo.ms.gov.br/ diariodoe/Index/Download/D09369_15_03_2017. Acesso em: 9 dez. 2017.

MATO GROSSO DO SUL (MS). MS Mostra MS - Economia Criativa - SECC/MS. Diário Oficial do Estado n. 9.485, p. 4-5 do dia 31 de agosto de 2017. 2017d. Disponível em: http://www.spdo.ms.gov.br/diariodoe/ Index/Download/D09485_31_08_2017. Acesso em: 10 dez. 2017.

MATO GROSSO DO SUL (MS). Chamada Pública SECTEI n. 03/2016. Diário Oficial do Estado n. 9.221, do dia 4 de agosto de 2016. 2016a. Disponível em: http://www.spdo.ms.gov.br/diariodoe/Index/Download/ D09221_04_08_2016. Acesso em: 10 dez.2017.

MATO GROSSO DO SUL (MS). Lei n. 4.975, de 29 de dezembro de 2016. Aprova a primeira revisão do Plano Plurianual para o período 2016/2019. 2016b. Disponível em:

http://www.transparencia.ms.gov.br/Content/Caderno/ARQUIVO_PPA\%202017\%20CADERNO\%20 COMPLETO.PDF.pdf. Acesso em: 9 dez. 2017.

MATO GROSSO DO SUL (MS). Lei n. 4.976, de 29 de dezembro de 2016. Estima a receita e fixa a despesa do Estado para o exercício financeiro de 2017. 2016c. Disponível em: http://www.transparencia.ms.gov.br/ Content/Caderno/ARQUIVO_CADERNO\%20LOA\%202017\%20COMPLETO.PDF.pdf. Acesso em: 9 dez. 2017.

MATO GROSSO DO SUL (MS). Chamada Pública SECTEI n. 02/2015. Diário Oficial do Estado n. 9.075, do dia 30 de dezembro de 2015. 2015a. Disponível em: http://www.spdo.ms.gov.br/diariodoe/Index/Download/ D09075_30_12_2015. Acesso em: 10 dez. 2017.

MATO GROSSO DO SUL (MS). Coordenadoria de Processamento de Licitação/SL/SAD. Diário Oficial do Estado n. 8.917, p. 15 do dia 12 de maio de 2015. 2015b. Disponível em: http://www.spdo.ms.gov.br/ diariodoe/Index/Download/D08917_12_05_2015. Acesso em: 9 dez. 2017.

MATO GROSSO DO SUL (MS). Decreto n. 14.169, de 27 de abril de 2015. Estabelece a estrutura básica da Secretaria de Estado de Cultura, Turismo, Empreendedorismo e Inovação (SECTEI), e dá outras providências. 2015c. Disponível em: http://www.spdo.ms.gov.br/diariodoe/Index/Download/D08908_28_04_2015. Acesso em: 9 dez. 2017. 
MATO GROSSO DO SUL (MS). Lei n. 4.806, de 21 de dezembro de 2015. Institui o Plano Plurianual para o período de 2016/2019. 2015d. Disponível em: http://www.transparencia.ms.gov.br/Content/Caderno/ Caderno\%20PPA\%202016.2019\%20Definitivo.pdf. Acesso em: 9 dez. 2017.

MATO GROSSO DO SUL (MS). Lei n. 4.807, de 21 de dezembro de 2015. Estima a receita e fixa a despesa do Estado para o exercício financeiro de 2016. 2015e. Disponível em: http://www.transparencia.ms.gov. br/Content/Caderno/Caderno\%20LOA\%202016\%20Definitivo.pdf. Acesso em: 9 dez. 2017.

MATO GROSSO DO SUL (MS). Portaria n. 044, de 19 de agosto de 2013. Homologa para a III Conferência Estadual de Cultura de Mato Grosso do Sul o seu Regimento Interno. 2013. Disponível em: http://www. spdo.ms.gov.br/diariodoe/Index/Download/DO8500_22_08_2013. Acesso em: 9 dez. 2017.

MINISTÉRIO DA CULTURA. Nova instrução normativa. Disponível em http://cultura.gov.br/nova-instrucaonormativa/. Acesso em: 5 dez. 2017.

MUNIZ, Carolina. Desenvolver a economia criativa será prioridade, diz ministro da Cultura. 2017. Disponível em: http://www1.folha.uol.com.br/mercado/2017/08/1912651-desenvolver-a-economia-criativa-seraprioridade-diz-ministro-da-cultura.shtml. Acesso em: 11 set. 2017.

NEUMAN, L. W. Social research methods: qualitative and quantitative approaches. Harlow, UK: Pearson, 2014.

PACHECO, Adriano Pereira de Castro. Economia Criativa e os pontos de cultura: uma agenda de cooperação para o desenvolvimento local. 2016. Dissertação (Mestrado em Administração)- Escola de Administração e Negócios, Universidade Federal de Mato Grosso do Sul, Campo Grande, MS, 2016.

PANCHERI, Vanessa. A arte da política: Mario de Andrade e o Departamento de Cultura de São Paulo (1935-1938) - uma gestão à frente do seu tempo. 2012. Trabalho de Conclusão de Curso (Graduação em Gestão de Políticas Públicas)- EACH/Universidade de São Paulo, São Paulo, 2012.

SAYERS, Dorothy. The other six deadly sins. Conferência dada em 23 de outubro de 1941. Disponível em: http://www.lectionarycentral.com/trinity07/sayers.html. Acesso em: 30 out. 2017.

SCHLESINGER, Philip. The creative economy: invention of a global orthodoxy. Journal Innovation: The European Journal of Social Science Research, v. 30, n. 1, p. 73-90, 2016. Disponível em: https://www. tandfonline.com/doi/full/10.1080/13511610.2016.1201651. Acesso em: 11 dez. 2017.

SEBRAE-MS. Relatório de Gestão 2016. Campo Grande, MS, 2017. Disponível em: http://www.sebrae. com.br/Sebrae/Portal\%20Sebrae/UFs/MS/Transpar\%C3\%AAncia/2017/Relat\%C3\%B3rio\%20de\%20 Gest\%C3\%A3o\%20SebraeMS\%202016\%20(completo).pdf. Acesso em: 11 dez. 2017.

SINCLAIR, Andrew. Arts and cultures: the history of the 50 years of the arts council of Great Britain. Londres: Sinclair-Stevenson, 1995.

TEIXEIRA, William; FERRAZ, Silvio. Música como ação. Revista Vórtex, Curitiba, PR, v. 5, n. 1, p. 1-12, 2017. Disponível em: http://periodicos.unespar.edu.br/index.php/vortex/article/view/1858/1153. Acesso em: 11 dez. de 2017. 


\section{Sobre os autores:}

Vanessa Pancheri Teixeira: Mestranda do Programa de Mestrado Profissional em Administração Pública em Rede, da Escola de Administração e Negócios da Universidade Federal de Mato Grosso do Sul (PROFIAP/ESAN/UFMS). Graduada em Gestão de Políticas Públicas pela EACH/USP. E-mail: van.pancheri@gmail.com, Orcid: http://orcid.org/0000-0002-1810-5519

William Teixeira: Doutor em Música pela Universidade de São Paulo (USP). Mestre em Música pela Universidade Estadual de Campinas (UNICAMP). Especialista em Teologia Bíblica pelo Centro Presbiteriano de Pós-Graduação "Andrew Jumper". Bacharel em Música com habilitação em violoncelo pela Universidade Estadual Paulista Júlio de Mesquita Filho (UNESP). Professor adjunto da Universidade Federal de Mato Grosso do Sul (UFMS). E-mail: william.teixeira@ufms.br, Orcid: http://orcid.org/0000-0002-6622-378X

Elcio Gustavo Benini: Doutor em Educação. Professor adjunto da Escola de Administração e Negócios (ESAN) da Universidade Federal de Mato Grosso do Sul (UFMS). Atua no Programa de Pós-Graduação stricto sensu em Administração e no mestrado profissional em Administração Pública (Profiap). Participa do Grupo de Estudos e Pesquisas sobre Organizações, Trabalho e Educação (GEPOTE). E-mail: elcio.benini@ufms.br, Orcid: http://orcid.org/0000-0002-0949-3062 